Res Publica. Revista de Historia de las Ideas Políticas

ISSN: $1576-4184$

\title{
"Vivas y desendeudadas nos queremos". Notas sobre la economía de la deuda y la guerra contra las mujeres en el capitalismo neoliberal latinoamericano
}

\author{
Matías Leandro Saidel*
}

Recibido: 4 de junio de 2018 / Aceptado: 4 de septiembre de 2018

Resumen. Este trabajo indaga la relación entre la economía de la deuda, como nuevo dispositivo de gobierno y desposesión de las poblaciones, y la polimorfa guerra contra las mujeres, que tiene en la proliferación de los femicidios su expresión más dramática. Ambos procesos, característicos del capitalismo neoliberal latinoamericano, encuentran su genealogía más inmediata en los terrorismos de estado y guerras antisubversivas que proliferaron en la región en los años 1970 y 1980, momento en que se pone en marcha una nueva forma de guerra de baja intensidad sobre ciertos sectores de la población y la crisis de la deuda, con sus efectos sobre las políticas públicas y la precarización generalizada de las condiciones de existencia. En dicho marco, la violencia contra las mujeres y el intento de recolonizar sus cuerpos-territorios recrudecen tras contextos de luchas sociales contra la neoliberalización, buscando imposibilitar la reproducción autónoma de la vida por fuera de las relaciones capitalistas.

Palabras clave: endeudamiento; guerra contra las mujeres; capitalismo neoliberal; común; Latinoamérica.

\section{[en] "We Want Us Alive and Unindebted". Some Comments on the Economy of Debt and the War against Women in Latin American Neoliberal Capitalism}

\begin{abstract}
This article inquires the relationship between the economy of debt as a new dispositive of government and dispossession of populations, and the polymorphic war against women, which most dramatic expression is the proliferation of femicides. Both processes, which characterize Latin American neoliberal capitalism, find their immediate genealogy in state terrorism and anti-subversive wars that proliferated in the region during the 1970 s and 80 s, in which a new form of low-intensity war on certain parts of the population and the generalized precarization of living conditions emerge. Hence, violence against women and the attempt to recolonize their bodies-territories become more intense, especially following contexts of social struggles against neoliberalization, seeking to impede the autonomous reproduction of life outside capitalist relations.
\end{abstract}

Keywords: Indebtedness; War against Women; Neoliberal Capitalism; Common; Latin America.

Sumario: 1. Introducción. 2. La deuda como mecanismo de desposesión y de control. 3. La guerra contra las mujeres en el capitalismo neoliberal latinoamericano. 4. La guerra contra las mujeres y las luchas por lo común.

\footnotetext{
* Investigador Asistente de la Universidad Católica de Santa Fe - Consejo Nacional de Investigaciones Científicas y Técnicas (Argentina); Profesor Titular de Filosofía Política de la Universidad Nacional de Entre Ríos (Argentina). msaidel@ucsf.edu.ar Agradezco los comentarios y sugerencias de los dos evaluadores anónimos.
} 
Cómo citar: Saidel, M. L. (2018). "Vivas y desendeudadas nos queremos”. Notas sobre la economía de la deuda y la guerra contra las mujeres en el capitalismo neoliberal latinoamericano, en Res publica 21.3, 585-602.

\section{Introducción}

En el día previo a la marcha de Ni una menos del 3 de Junio de 2017, se realizó una acción en el Banco Central de la República Argentina que, además de pancartas alusivas a los efectos nocivos de la deuda, incluyó la difusión de un texto titulado "Vivas y desendeudadas nos queremos". En dicha acción y en dicho panfleto, el colectivo en cuestión, que es el que mayor capacidad de movilización social ha tenido en los últimos años, ponía en evidencia una estrecha conexión entre economía de la deuda y violencia femicida. Este documento apareció poco después de la marcha contra el beneficio de reducción de penas, conocido como $2 \times 1$, que algunos jueces habían empezado a aplicar a condenados por delitos de lesa humanidad cometidos durante la última dictadura militar (1976-1983), experiencia política que, junto con el terrorismo de Estado, implicó el primer gran hito del endeudamiento público masivo que afecta a la Argentina actual en el marco del intento de aplicación de reformas neoliberales ${ }^{1}$. Las feministas establecían así una clara continuidad entre la violencia genocida en Latinoamérica, la sujeción que implica la deuda tanto privada como pública y la violencia machista que tiene como manifestación extrema el femicidio.

Siguiendo dichas conexiones, en este trabajo partiremos de la hipótesis de que la deuda funciona en el capitalismo neoliberal como una nueva lógica de desposesión y gobierno, que redefine los términos de la guerra en el seno de las poblaciones ${ }^{2}$. Señalaremos que en dicho marco la actual guerra contra las mujeres no tiene que ver con una misoginia atemporal sino con una configuración específica del capitalismo neoliberal en nuestra región. Por último, marcaremos el carácter reaccionario de dichas violencias, en la medida en que recrudecen tras contextos de luchas sociales que ponen en tela de juicio los procesos de neoliberalización y buscan imposibilitar la reproducción autónoma de la vida por fuera de las relaciones capitalistas, recolonizando los cuerpos de las mujeres.

\section{La deuda como mecanismo de desposesión y de control}

Uno de los análisis más lúcidos del neoliberalismo es el que elaboró en los últimos años Maurizio Lazzarato, quien puso de manifiesto el modo en que el empresario de sí mismo y el capital humano, figuras paradigmáticas de la gubernamentalidad neoli-

\footnotetext{
Sobre la relación entre la violencia estatal, la aplicación de reformas neoliberales y la trampa de la deuda véase D. Harvey, Breve historia del neoliberalismo, Madrid, Akal, 2007; N. Klein, La doctrina del "shock": El auge del capitalismo del desastre. Barcelona, Paidós, 2007.

2 Como hemos trabajado en detalle en otros escritos, si la interpretación del neoliberalismo en términos de desposesión remite a la obra citada de David Harvey, la lectura en términos de gubernamentalidad tiene como referencia central el trabajo de M. Foucault, Nacimiento de la biopolitica: Curso en el College de France (1978-1979). México, D.F. Fondo de Cultura Económica, 2008. Otra referencia fundamental en este sentido es la de P. Dardot y Ch. Laval, La nueva razón del mundo. Ensayo sobre la sociedad neoliberal, Barcelona, Gedisa, 2014.
} 
beral estudiadas a partir de Foucault ${ }^{3}$, tenían como reverso la producción de un hombre endeudado. En tanto dispositivo de control, la deuda articula formas violentas de desposesión y expropiación de plusvalía con la producción de una subjetividad que se entiende a sí misma en términos de capital y de empresa y que, gracias a la introducción de la lógica económica en cada ámbito decisional y a la sistematicidad de sus respuestas en relación con las modificaciones del medio, resultaría eminentemente gobernable ${ }^{4}$.

En realidad, este dispositivo es antiquísimo porque, como muestran las investigaciones antropológicas de David Graeber -que desmiente el mito del trueque sobre el que se funda la economía liberal- los intercambios económicos siempre han implicado la producción de deuda, incluso mucho antes de la acuñación de moneda- . En ese marco, la moneda no surge para facilitar el comercio sino la conquista, y está íntimamente vinculada a una autoridad política armada a la que se debe reembolsar a través de los impuestos ${ }^{5}$. Por lo tanto, la moneda no es simplemente un medio que facilita nuestra propensión natural al intercambio, como supone la economía política liberal al menos desde Adam Smith, sino un dispositivo de regulación, anticipación y control de las conductas. Esto se hace más evidente si consideramos que nuestras propias ideas morales y la autoconciencia derivarían de la deuda. Como recuerdan tanto Graeber como Lazzarato, siguiendo a Nietzsche, la propia noción religiosa y moral de culpa (Schuld) deriva de las deudas (Schulden) ${ }^{6}$. La deuda/culpa entonces produce una captura de los posibles, en la medida en que fabrica al hombre como un animal capaz de prometer y de crearse una conciencia y una memoria del futuro. Una vez sometida a los imperativos de la deuda, la existencia en su totalidad debe organizarse con vistas al reembolso ${ }^{7}$.

No es casual que el capitalismo neoliberal, favorecido por la financiarización cada vez más insidiosa de la economía y de la vida que se produjo ininterrumpidamente desde 1971 (año en el que Nixon declara la inconvertibilidad dólar-oro, desanclando la emisión de moneda de cualquier sujeción a una garantía tangible) a nuestros días, recurra sistemáticamente al endeudamiento como un método no solo de obtención de enormes rentas para los grandes acreedores sino también de anticipación de los comportamientos futuros y de extorsión de las poblaciones. Dicho rol preponderante

\footnotetext{
M. Foucault, op. cit.

Ibidem., p. 310

Como muestra Graeber, los registros de escritura cuneiforme en la Mesopotamia muestran que el crédito existe hace al menos 5000 años, donde el intercambio, que no tiene la forma del trueque, en general tampoco implica el uso habitual de metales. La acuñación surge entre los s. VIII AC y VI DC para pagar un anticipo a los ejércitos, con lo cual queda clara la relación entre moneda y guerra, entre autoridad política y deuda. De hecho, los miembros de un pueblo vencido por otro en la guerra se han visto obligados históricamente a aceptar la esclavitud porque le debían al otro la vida. Graeber señala: "Si algo enseña la historia, es que no hay mejor manera de justificar relaciones basadas en la violencia, para hacerlas parecer éticas, que darles un nuevo marco en el lenguaje de la deuda, sobre todo porque inmediatamente hace parecer que es la víctima la que ha hecho algo mal... Durante miles de años los violentos han sabido convencer a sus víctimas de que les deben algo. Como mínimo, que «les deben sus vidas», una frase hecha, por no haberlos matado". D. Graeber, En deuda. Una historia alternativa de la economía, Barcelona, Ariel, 2012, p. 12.

6 Por lo demás, Graeber recuerda que las grandes religiones del mundo moderno surgen conjuntamente con la acuñación de moneda, tal vez como reacción o contrapeso a los excesos de la economía monetaria.

7 M. Lazzarato, La fábrica del hombre endeudado, Buenos Aires, Amorrortu, 2013. A este respecto, cabe señalar que, a diferencia de Lazzarato, Graeber toma distancia de la genealogía nietzscheana, pues se acerca demasiado a una teoría de la deuda primordial que asume una antropología burguesa como norma universal, algo no válido para otras civilizaciones. D. Graeber, op. cit., p. 102ss
} 
de la deuda primero se dio a nivel global en el ámbito público, desde fines de los '70, y luego se hizo masivo en el ámbito privado, en las últimas dos décadas 8 .

En efecto, sabemos que la estanflación de los '70 y la disponibilidad de una gran liquidez por parte de los bancos norteamericanos donde se depositaron los dólares generados por la suba de los precios del petróleo de la OPEP en 1973 hizo que muchos países, especialmente en América Latina, recurrieran al crédito externo para financiar sus déficit. La suba de tasas de interés que se produjo en 1979, conocida como shock Volcker, fue el detonante de la crisis de la deuda latinoamericana de los '80. De hecho, México fue quizás un caso testigo de cómo la deuda podía ser un mecanismo utilizado por la nueva ortodoxia neoliberal del FMI y del Banco Mundial y del Tesoro de los EEUU, para obligar a los países endeudados a introducir reformas neoliberales a cambio de refinanciar las deudas ${ }^{9}$. Las medidas que fueron introducidas progresivamente en México y luego en el resto de América Latina, algunas de las cuales ya habían sido ensayadas en el cono sur, implicaron siempre ajustes estructurales que contenían medidas como: privatización de empresas y servicios públicos, liberación de las tarifas, apertura comercial y financiera, baja de impuestos a las corporaciones, reducción del salario real y del empleo público, devaluación de la moneda, etc. Si bien la justificación que se daba y se sigue dando para tomar estas medidas pasa por mejorar la competitividad de las naciones y generar, vía inversión extranjera, un ciclo de crecimiento que favorezca la reducción progresiva de la deuda pública y una mejora de la calidad de vida de la población, el efecto siempre ha sido el contrario: recesión, destrucción del aparato productivo, aumento estrepitoso del desempleo, la pobreza y la desigualdad, concentración económica, aumento de los precios de bienes básicos, menor capacidad de recaudación del Estado, mayor déficit relativo, y necesidad de recurrir a más endeudamiento para cubrirlo, ingresando en un ciclo de deuda infinita e impagable ${ }^{10}$.

Teniendo en cuenta la tesis de Harvey del neoliberalismo como un proyecto para restaurar el poder de la clase capitalista o las propias hipótesis de Lazzarato sobre el rol que tiene la deuda en la lucha de clases hodierna ${ }^{11}$, cabe señalar que dichas políticas han tenido como efecto, por un lado, la producción de un "hombre endeu-

\footnotetext{
W. Davies, “The new neoliberalism”, New Left Review, Sep/Oct 2016.

D. Harvey, op. cit., p. 36, 82, 109-115.
}

10 Como señala A. López Bolaños, el ajuste impulsado por el FMI en México a mediados de los 80, antecedente inmediato del TLCAN, "se presentó como el mecanismo idóneo para «dinamizar» la economía, impulsar el crecimiento y mejorar la calidad de vida de los mexicanos. Pero el ajuste tenía como pretensión real desvalorizar a la fuerza de trabajo, eliminar las restricciones a la libre movilidad del capital y con ello impulsar el proceso de acumulación a áreas rentables de la periferia, que en el caso mexicano, profundizó su condición dependiente al ciclo económico de Estados Unidos". "México. La continuidad y profundización del despojo neoliberal. Balance de la economía a partir del Tratado de Libre Comercio de América del Norte (TLCAN) 1994-2014", en Rojas Villagra, L. (coord.), Neoliberalismo en América Latina. Crisis, tendencias y alternativas, Buenos Aires, CLACSO, 2015, p. 223. Algo similar sucedió con las políticas neoliberales en Argentina, dando lugar a una des-industralización y sobre-endeudamiento que terminaría con confiscaciones de ahorros y una declaración de cesación de pagos hacia fines de 2001. Cf. F. López Segrera, "Situación actual y perspectivas del posneoliberalismo", en Id., América Latina: Crisis del posneoliberalismo y ascenso de la nueva derecha. Ciudad de Buenos Aires, CLACSO; Ediciones CICCUS, 2016, pp. 48ss.

11 Cf. M. Lazzarato, op. cit. Y D. Harvey, op. cit., quien basa sus afirmaciones en G. Duménil y D. Lévy, Crise et sortie de crise: Ordre et désordres néolibéraux, Paris, PUF, 2000. De esta misma opinión es J. Puello Socarrás, quien señala que "Desde la década de 1970 y hasta el día de hoy, el neoliberalismo es, por antonomasia, la estrategia ofensiva y contrarrevolucionaria del Capital (contra el Trabajo)". "Neoliberalismo, antineoliberalismo, nuevo neoliberalismo. Episodios y trayectorias económico-políticas suramericanas (1973-2015)” en Rojas Villagra, op. cit., p. 22 
dado", responsable de su propia suerte y obligado al reembolso, y, por otro, asegurar la posición de las minorías cada vez más exiguas y poderosas que controlan la economía mundial. Por eso, como lo reconoce Warren Buffett, el tercer sujeto más rico del planeta, la clase a la que pertenece está ganando la guerra. El mismo empresario señala que el Estado debería dejar de mimar a los ricos, por ejemplo a través de bajas sistemáticas de impuestos a los sectores de mayores ingresos y capita ${ }^{12}$. De esta manera, el oráculo de Omaha nos recuerda que las finanzas y, más específicamente la economía de la deuda, es el dispositivo clave de control de nuestras vidas a través del cual se da hoy la lucha de clases ${ }^{13}$. De hecho, si la deuda implica una captura de los posibles, si lo único seguro es que en el futuro debemos reembolsar nuestras deudas sin importar cómo, si nuestros ahorros, aportes previsionales, salud, educación, etc. pasan a estar sujetos a los vaivenes de la bolsa y a las evaluaciones de las agencias calificadoras que son parte del bloque de poder neoliberal, entonces se vuelve claro por qué podemos imaginar el fin del mundo pero no el fin del capitalismo ${ }^{14}$.

En ese marco, para Lazzarato lo que nos obliga a comportarnos como un capital que debe ser administrado de manera eficiente (capital humano) y adoptar un ethos empresarial es la condición de precariedad existencial a la que nos condena la deuda.

En la economía de la deuda, llegar a ser capital humano o empresario de sí mismo significa $[\ldots]$ hacerse cargo de la pobreza, el desempleo, la precariedad, los ingresos mínimos, los bajos salarios, las jubilaciones cercenadas, etc., como si fueran "recursos" e "inversiones" del individuo que deben administrarse como un capital, "SU" capital. Según se advierte hoy claramente, los conceptos de «empresario de sí mismo» y "capital humano" deben interpretarse a partir de la relación acreedordeudor, o sea, la relación de poder más general y desterritorializada merced a la cual el bloque de poder neoliberal gobierna la lucha de $\operatorname{clases}^{15}$.

Lejos de una separación demasiado frecuente entre gubernamentalidad/economía y guerra, para Lazzarato la deuda es una de las formas más destructivas que adquiere la guerra en nuestro presente. De hecho, recupera la tesis de dos coroneles de la aviación China, Qiao Liang y Wang Xiangsui, que señala que las guerras financieras (no sanguinarias) pueden ser más destructivas que las guerras convencionales (sanguinarias). En ese sentido, la matriz de las guerras contemporáneas sería la guerra colonial:

La economía de la deuda transforma la "guerra civil mundial" (Schmitt, Arendt) en una imbricación de guerras civiles: guerras de clase, guerras neocoloniales contra las minorías, guerras contra las mujeres, guerras de subjetividad. La matriz de estas guerras civiles es la guerra colonial... una guerra en y contra la población,

12 W. Buffett, "The rich have won the class war". Entrevista a W. Buffett, por Alison Kosik para CNN el 30 de septiembre de 2011, video disponible en http://money.cnn.com/video/news/2011/09/30/n_buffett_class_warfare. cnnmoney/ y "Stop Coddling the Super-Rich", en New York Times, 14 de Agosto de 2011, diponible en http:// www.nytimes.com/2011/08/15/opinion/stop-coddling-the-super-rich.html.

13 En realidad, Graeber sostiene que ya en la Antigüedad la lucha de clases tomaba la forma de la deuda, motivo por el cual Moses Finley solía decir que "todos los movimientos revolucionarios de la Antigüedad tenían un mismo programa: «Cancelar las deudas y redistribuir la tierra»”. G. Graeber, op. cit., p. 16.

14 Frase que aparece tematizada en Frederick Jameson (La ciudad futura, New Left Review, n²1, mayo-junio 2003, pp. 91-106), Slavoj Zizek (passim) y Mark Fisher (Realismo capitalista. ¿No hay alternativa?, Buenos Aires, Caja Negra, 2016).

15 M. Lazzarato, La fábrica del hombre endeudado, p. 58. 
donde las distinciones entre paz y guerra, entre combatientes y no combatientes, entre lo económico, lo político y lo militar nunca tuvo lugar. La guerra colonial en y contra las poblaciones es el modelo de guerra que el Capital financiero ha desatado a partir de los años 1970, en nombre de un neoliberalismo combativo. Su guerra será a la vez fractal y transversal ${ }^{16}$.

Estas reflexiones de Lazzarato y Alliez coinciden en buena medida con el trabajo de pensadoras feministas que trabajan desde la realidad latinoamericana. En ese sentido, Verónica Gago, junto al colectivo "Ni una menos", pone de manifiesto la conexión entre economía de la deuda y guerra contra las mujeres. Al mismo tiempo, Rita Segato y Jules Falquet analizan la continuidad entre las guerras antisubversivas y la ola de feminicidios que sacuden a diversos territorios latinoamericanos, como México, donde la crisis de la deuda y las reformas neoliberales se impusieron tempranamente, y Guatemala, donde el extractivismo ${ }^{17}$ y la violencia paraestatal ${ }^{18}$ marcan un continuum entre la guerra civil y el genocidio maya de los ' 80 y las reformas neoliberales actuales ${ }^{19}$. En sintonía con lo planteado por Lazzarato y Alliez, Falquet

16 É. Alliez \& M. Lazzarato, Guerres et capital, Paris, Éditions Amsterdam, 2016, p. 29.

17 Por extractivismo me refiero aquí fundamentalmente a "actividades económicas que se basan en la explotación de los bienes comunes naturales" que, con poco o nulo procesamiento, "son comercializados en el mercado mundial” (J. Seoane, Modelo extractivo y acumulación por despojo, en J. Seoane, E. Taddei y C. Algranati, Extractivismo, despojo y crisis climática. Desafios para los movimientos sociales y los proyectos emancipatorios de Nuestra América, Buenos Aires, Herramienta, 2013), generando una reprimarización de las economías latinoamericanas, y reforzando su sujeción a los vaivenes de los precios internacionales de los commodities. No obstante, me parece sugerente insertar dicho concepto en otro más amplio que caracteriza al capitalismo actual basado en las plataformas digitales, la revolución en la logística y la renta financiera. Sobre el primer sentido del concepto véase, por ejemplo M. Svampa, "Del «consenso de Washington» al «consenso de los commodities»”, en M. Svampa, y E. Viale. Maldesarrollo: La Argentina del extractivismo y el despojo, Buenos Aires, Katz Editores, 2014. En el sentido más amplio, cfr. V. Gago \& S. Mezzadra. "Para una crítica de las operaciones extractivas del capital. Patrón de acumulación y luchas sociales en el tiempo de la financiarización", Nueva Sociedad, No. 255, enero-febrero de 2015 y S. Mezzadra y B. Neilson, "On the multiple frontiers of extraction: excavating contemporary capitalism”, Cultural Studies, 31:2-3, 2017, pp. 185-204, DOI: 10.1080/09502386.2017.1303425.

18 Por violencia paraestatal me refiero de manera amplia al uso de la coerción armada y la represión por parte de grupos que son incentivados o tolerados por los Estados y cuyo accionar muchas veces no puede ser controlado por las propias fuerzas represivas legales. Esto incluye tanto el uso de fuerzas paramilitares como parapoliciales. Para una definición de la paraestatalidad véase, por ejemplo, J. L. Besoky, "Violencia paraestatal y organizaciones de derecha. Aportes para repensar el entramado represivo en la Argentina, 1970-1976", Nuevo Mundo Mundos Nuevos, http://journals.openedition.org/nuevomundo/68974 ; DOI : 10.4000/nuevomundo.68974.

19 Como sabemos, el concepto de genocidio divide aguas en las ciencias sociales, ya que existen quienes abogan por un uso restringido del término, como el estudioso de la memoria social Hugo Vezzetti, ("Verdad jurídica y verdad histórica. Condiciones, usos y límites de la figura del «genocidio»”, en C. Hilb, Ph.-J. Salazar y L. G. Martín, eds. Lesa humanidad: Argentina y Sudáfrica: reflexiones después del Mal. Buenos Aires, Katz, 2015) y la filósofa política Claudia Hilb (Usos del pasado: Qué hacemos hoy con los setenta, Buenos Aires, Siglo Veintiuno Editores, 2013) y otros que lo usan de manera más amplia, como Daniel Feierstein, quien lo entiende como una práctica social y lo utiliza para casos como el argentino, donde el asesinato y desaparición de 30000 seres humanos obedeció a motivos políticos. (Cf. D. Feierstein (comp.), Genocidio, La administración de la muerte en la modernidad, Caseros, UNTREF, 2005; El genocidio como práctica social: Entre el nazismo y la experiencia argentina. Hacia un análisis del aniquilamiento como reorganizador de las relaciones sociales. Buenos Aires, Fondo de Cultura Económica, 2007). Si bien son intenciones políticas las que definen muchas veces el uso del término, cabe puntualizar que la Convención para la Prevención y Sanción del Delito de Genocidio, realizada por las Naciones Unidas en 1948, entiende por genocidio actos (matanzas, traslados, impedimiento de nacimientos, etc.) cometidos con la intención de destruir total o parcialmente a un grupo nacional, étnico, racial o religioso como tal. Dicha convención excluyó explícitamente de la definición a los grupos políticos -que estaban presentes en la definición del creador del término, Rafael Lemkin- para conseguir el aval 
también señala que la diferencia entre la guerra de baja intensidad y la guerra clásica, es que la primera "toma como blanco a la población no combatiente y que no está formalmente declarada, lo que impide a la población buscar amparo en las mínimas reglas de derecho que rigen los conflictos clásicos" ${ }^{20}$.

En ese sentido, si bien hay que diferenciar claramente el tipo de violencia que implica el femicidio del endeudamiento tomados de manera aislada, ambas prácticas no solo están vinculadas en las nuevas formas de guerras contra las mujeres, sino que en ambos casos se toma a la población y sus divisiones como su blanco.

\section{La guerra contra las mujeres en el capitalismo neoliberal latinoamericano}

Uno de los pocos ámbitos intelectuales donde la violencia ha sido pensada no sólo como momento fundacional de los regímenes neoliberales ni tan solo como un elemento extrínseco y aleatorio sino también como un modo de desposesión y gobierno de las subjetividades es el feminista. Si bien el patriarcado (al igual que la deuda) es una forma de poder arcaica, trabajos como los de Rita Segato, Sayak Valencia, y Jules Falquet, entre otras, tienen el mérito heurístico y político de situar el asesinato sistemático de mujeres (y no solo) en territorios como la frontera norte de México o Guatemala en un contexto de violencia más amplio que obedece a una historia precedente y a las transformaciones más generales en el régimen de poder del capitalismo neoliberal, y no reducen el problema a vanas explicaciones culturalistas o a una misoginia universal y transhistórica ${ }^{21}$. Como afirma Falquet, los feminicidios "constituyen a la vez una "nueva" forma de violencia específica del neoliberalismo tal como se desarrolla hoy en México, que le resulta muy útil, y que tiene(n) su origen en la historia de larga duración del control político-militar específico de este país"22.

de la URSS. (Cf. H. Folgueiro, "El crimen de genocidio en el derecho internacional", en Feierstein, Daniel y Levy, Guillermo; Hasta que la muerte nos separe, La Plata, Ediciones Al Margen, 2004). Por ello, si bien las consecuencias jurídicas del genocidio equivalen a cualquier otro delito de lesa humanidad, las ciencias sociales ha elaborado el concepto de politicidio para caracterizar la erradicación de grupos políticos. En términos prácticos, una diferencia clave sería que en el genocidio se suele matar a los miembros del grupo y a sus familias, mientras que en el politicidio esto no suele suceder. Sin embargo, en muchos casos, más que la naturaleza del crimen lo que cambia es el público objetivo y los motivos para perseguir y aniquilar a un colectivo determinado. "En los genocidios, los grupos víctima son definidos por sus perpetradores en primer término en función de las características comunales. En el politicidio, en cambio, los grupos son definidos principalmente en términos de su oposición política al régimen y a los grupos dominantes.” (B. Harff, “¿No se aprendieron las lecciones del Holocausto?", en D. Feierstein (Comp.), op. cit., p. 174). Como vemos, a partir de esta definición, mientras que en el caso argentino la definición de politicidio podría ser más precisa científicamente que la de genocidio, ambos términos servirían para caracterizar el caso guatemalteco, frecuentemente caracterizado como genocidio, etnocidio o democidio, ya que en el asesinato, desplazamiento, desapariciones y violaciones de miembros de las etnias mayas que fueron prácticamente destruidas, se mezclan motivos políticos, económicos y raciales.

20 J. Falquet, Pax neoliberalia: perspectivas feministas sobre (la reorganización de) la violencia contra las mujeres. Ciudad Autónoma de Buenos Aires, Madreselva, 2017, p. 48.

21 En este sentido, López Segrera recuerda que América Latina tiene la mayor tasa de homicidios y secuestros del mundo, y la peligrosa tendencia que, como recuerda Harvey ( op. cit), transformó México de un país seguro en una de las geografías más inseguras del mundo. "La tasa de homicidios en la región se sitúa en 26 homicidios, tres veces más que en Europa, y se dispara por encima de los 40 homicidios en países como El Salvador, Jamaica, Honduras, Venezuela y Colombia. También México pertenece a este grupo. Aunque lo más preocupante es la tendencia: entre 1980 y 2006, este índice pasó de 13 a 25 en la región, y se prevé que llegue a 2030 con 30 homicidios por cada 100.000 habitantes". F. López Segrera, “América latina: crisis del posneoliberalismo y ascenso de la nueva derecha", en Ibidem, op. cit., p. 32, n.23.

22 Ibidem, p. 87. 
Según estas investigaciones, fuerzas militares y paramilitares utilizadas inicialmente en la guerra antisubversiva de los '70 y '80, se han transformado en bandas armadas o fuerzas paraestatales que están vinculadas a una serie de negocios como el narcotráfico, venta de armas y el tráfico de personas. Estos grupos se disputan el control territorial en distintas geografías latinoamericanas ${ }^{23}$. En ese contexto, la violencia contra las mujeres puede ser explicada en relación a disputas de dinero, poder y soberanía en un marco donde el Estado o bien se ausenta voluntariamente por los beneficios indirectos que obtiene, o bien directamente apoya el saqueo y la expropiación de los territorios-cuerpos, o bien disputa la soberanía con las bandas criminales, generándose un terror en la población que beneficia a ambos bandos.

En ese sentido, las nuevas formas que asume la guerra se vinculan con la importancia que ha cobrado lo que Segato llama "segundo estado" o "segunda realidad". Mientras que la "primera realidad" tiene que ver con todo aquello declarado al Estado, es decir, con la economía y la ciudadanía formales, las instituciones republicanas y las fuerzas represivas y judiciales legalmente constituidas, la segunda realidad remite a una economía sumergida que cuenta con reglas y fuerzas represivas propias "es decir, corporaciones armadas ocupadas en proteger para sus "dueños" la propiedad sobre la riqueza incalculable que en ese universo se produce y administra" 24 . Es en el marco de estas economías criminales y sus disputas de dinero y soberanía que han crecido exponencialmente los homicidios y hechos de violencia que tienen a poblaciones indefensas como sus víctimas principales. Por eso Rita Segato insiste en que la violencia femicida en estos casos no se reduce a violencia sexual: lo que está en juego es más bien el control del territorio y de la "segunda realidad" a través de un lenguaje que utiliza el terror como signo que se inscribe en los cuerpos violentados. Tomando como punto de partida una investigación realizada con violadores de las cárceles de Brasi1 ${ }^{25}$, Segato teoriza que en casos donde se viola, mutila y mata a quienes, como las mujeres de Juárez, no tienen relación alguna con los perpetradores, lo que está en juego no es una satisfacción de pulsiones sexuales sino una nueva forma de ejercicio del poder que llama dueñidad, "una nueva forma de señorío resultante de la aceleración de la concentración y de la expansión de una esfera de control de la vida" que describe como paraestatal ${ }^{26}$. Segato recuerda que precisamente en las geografías más violentas, como en México y Centroamérica, con amplios territorios controlados por cárteles, maras y bandas armadas de distinto tipo, la violencia contra las mujeres tiene poco que ver incluso cuantitativamente con problemas vinculares. Por eso sostiene que el cuerpo de la mujer violada, mutilada y asesinada se presenta como el soporte de un mensaje hacia bandas rivales y a la sociedad en su conjunto.

En esos crímenes [contra mujeres y niños], el capital, en su forma contemporánea, expresa la existencia de un orden regido por el arbitrio, exhibiendo el espectáculo

\footnotetext{
23 Cabe destacar que dichas fuerzas fueron educadas en la producción del terror en el seno de la población. En el caso guatemalteco, esto incluía la violación como instrumento de guerra, algo que fue replicado masivamente en Bosnia-Herzegovina, en Ruanda y en el Congo.

24 R. Segato, "Las nuevas formas de la guerra y el cuerpo de las mujeres." Sociedade e Estado 29, no. 2 (2014): 341-71, p. 357.

25 R. Segato, Las estructuras elementales de la violencia, Bernal, Universidad Nacional de Quilmes, 2003.

26 R. Segato, La guerra contra las mujeres. Madrid, Traficantes de Sueños, 2016, p. 17.
} 
de la posibilidad de una existencia sin gramática institucional o, en otras palabras, de falencia institucional inevitable ante niveles de concentración de riqueza sin precedentes $^{27}$.

Se trata de una violencia pedagógica y expresiva, basada en la crueldad: "mediante este tipo de violencia el poder se expresa, se exhibe y se consolida de forma truculenta ante la mirada pública, por lo tanto representando un tipo de violencia expresiva y no instrumental" 28 .

Este tipo de violencia forma parte de lo que Sayak Valencia llama capitalismo gore para pensar el lado oscuro de la globalización neoliberal, centrándose en el caso de la también fronteriza Tijuana ${ }^{29}$. Valencia muestra que en estos territorios la violencia funcionaría como herramienta de mercado o de emprendimiento, medio de supervivencia alternativo frente a la situación de precariedad laboral y existencial, y pieza clave de la autoafirmación masculina. Ello se da en el marco de la transformación del Estado-nación en Estado-mercado y, en el caso particular de México, en narco-Estado, donde los cárteles de la droga funcionan como verdaderas empresas transnacionales.

En efecto, Valencia vincula de manera directa la violencia del capitalismo gore con las dinámicas de la globalización neoliberal, donde las nuevas formas de gubernamentalidad extienden la racionalidad económica a todos los ámbitos de la vida con la consiguiente precarización laboral mundial ${ }^{30}$. En ese marco, las prácticas gore responden a uno de los imperativos de legitimación del (neo)liberalismo: la idea del self-made-man o, más foucaulteanamente, empresario de sí mismo. Esto se vincula de manera directa con la redefinición del rol del Estado, que ya no busca asegurar a la población contra los riesgos que aquejan a la existencia sino promover subjetividades responsables de su propia suerte que estén dispuestas a vivir peligrosamente. En ese sentido, Valencia sostiene que

[...] el Estado en la era global puede entenderse más como una política interestatal mundial que al tiempo que elimina sus fronteras económicas redobla sus fronteras internas y agudiza sus sistemas de vigilancia. Dicha proliferación de fronteras, vigilancia y controles internos aumenta los costes, el auge y la demanda de mercancías gore: tráfico de drogas, personas, contratación de sicarios, seguridad privada gestionada por las mafias, etc. ${ }^{31}$.

27 Ibidem.

28 Ibidem, p. 18

29 Señala Valencia: “con capitalismo gore nos referimos al derramamiento de sangre explícito e injustificado (como precio a pagar por el Tercer Mundo que se aferra a seguir las lógicas del capitalismo, cada vez más exigentes), al altísimo porcentaje de vísceras y desmembramientos, frecuentemente mezclados con el crimen organizado, el género y los usos predatorios de los cuerpos, todo esto por medio de la violencia más explícita como herramienta de necroempoderamiento (...) en el capitalismo gore... la destrucción del cuerpo se convierte en sí mismo en el producto, en la mercancía, y la acumulación ahora es sólo posible a través de contabilizar el número de muertos, ya que la muerte se ha convertido en el negocio más rentable”. S. Valencia, Capitalismo gore. $1^{\mathrm{a}}$ ed. Barcelona, Melusina, 2010, pp. 15-16.

30 Valencia entiende como componentes clave de la globalización la desregulación del mercado laboral, la desterritorialización de la producción, la "Decodificación de flujos financieros por la aplicación exacerbada de la política neo-liberal" y las "Estrategias aplicadas para que el dinero viaje a la velocidad de la información". Ibidem, p. 31.

31 Ibidem, p. 30. 
Según Valencia, en el capitalismo actual, las nuevas formas de control y vigilancia ejercidos sobre la vida no solo son toleradas sino incluso demandadas por una conciencia social acrítica e hiperconsumista generada por el maridaje neoliberal entre economía, política y globalización. Dichos deseos consumistas, generados en el marco del mercado-nación, se extienden a lugares donde difícilmente pueden ser satisfechos por la vía legal. De hecho, Valencia señala que en el Tercer Mundo, "el estallido del Estado se ha dividido entre la integración de las demandas neoliberales y la interpretación literal de estas demandas por parte de la población tercermundista que ha devenido en la creación de un Estado alterno hiperconsumista y violento" ${ }^{32}$.

Esa ideología hiperconsumista se instaló de manera paralela a los procesos de desarticulación social y empobrecimiento de amplias capas de la población latinoamericana en el marco de la crisis de la deuda e imposición de medidas neoliberales que hemos comentado más arriba. En ese contexto, nuevas formas de economía ilegal o directamente criminal han venido a llenar el vacío dejado por la carencia de oportunidades en el mercado formal y la desintegración del magro Estado benefactor preexistente. Según Valencia, en el caso mexicano, el aumento de la pobreza fortaleció "la popularización de la economía criminal y el uso de la violencia como herramienta mercantil (...) un camino paralelo que trazó la ruta hacia el capitalismo gore"

En las realidades fronterizas analizadas por Valencia, el hiperconsumismo reconfigura lo social y lo axiológico, destacándose la pérdida del valor de la vida, y la emergencia de sujetos endriagos, para quienes la violencia es una herramienta de trabajo, de autoafirmación y de supervivencia. En ese marco necropolítico, los endriagos disputan al Estado la seguridad, el territorio y la población ${ }^{34}$. Como ya hemos señalado, Valencia vincula explícitamente la emergencia de este capitalismo gore a las lógicas propias de la globalización financiera con sus prácticas extractivas y al puño visible que la hace funcionar:

Estas prácticas se han radicalizado con el advenimiento de la globalización dado que ésta se funda en lógicas predatorias que, junto a la espectralización y la especulación en los mercados financieros, se desarrollan y ejecutan prácticas de violencia radical ${ }^{35}$.

En dicho marco, no solo hay una íntima vinculación entre economías legales e ilegales, sino que unas y otras se sustentan en los mismos valores. Tanto los jefes de los cárteles como los especialistas en el ejercicio de la violencia son auténticos emprendedores dispuestos a innovar, reinventarse y asumir riesgos en un contexto de demanda creciente de los bienes y servicios que ofrecen. Es decir, están perfectamente a tono con lo que la época neoliberal exige de todos nosotros y particularmente de las poblaciones más precarizadas: asumir un ethos empresarial para poder acceder al consumo.

32 Ibidem, p. 34.

33 Ibidem., p. 36 En una línea similar, López Bolaños señala que "Los resultados del TLCAN para México [...] involucran crisis agrícola, rezago industrial, retroceso del poder adquisitivo del salario, quiebra de empresas, concentración de los sectores y empresas exportadoras, importación indiscriminada, fuga de capitales, devaluaciones recurrentes y el auge de flujos ilícitos de capital. En suma, un despojo financiero, laboral y territorial". Op. cit., p. 224-225

34 En clara alusión al texto homónimo de Michel Foucault, donde inaugura su historia de la gubernamentalidad en occidente. Cf. M. Foucault, Seguridad, Territorio, Población: Curso en el Collége de France (1977-1978), México, Fondo de Cultura Económica, 2006.

35 S. Valencia, op. cit., p. 17 
Algunas de las características distintivas del emprendedor/a son: la innovación, la flexibilidad, el dinamismo, la capacidad para asumir riesgos, la creatividad y la orientación al crecimiento. Bajo estas características los sujetos endriagos, es decir, emprendedores del capitalismo gore, crean una amalgama entre emprendedores económicos, emprendedores políticos y especialistas de la violencia ${ }^{36}$.

Como señalábamos, no es casual que este tipo de necroemprendimientos tengan lugar en estas geografías. En ese sentido, Jules Falquet nos recuerda el carácter estratégico de México en general y de su frontera norte en particular como fuente de materias primas y de mano de obra para Estados Unidos. En particular, la frontera norte

[...] es especialmente emblemática de las lógicas de industrialización y luego de desarrollo de las zonas francas características del neoliberalismo. Ilustra con especial claridad la forma en que son puestas a trabajar diferentes categorías de mano de obra, en el centro de las cuales encontramos a lxs migrantes y a las mujeres, generalmente proletarizadas y racializadas: precisamente el tipo de personas que son el blanco de los feminicidios en Juárez ${ }^{37}$.

A diferencia de Segato, Falquet sostiene que la violencia femicida tiene un componente instrumental decisivo y no tiene como destinatarios centrales a otras bandas. Dicha violencia va dirigida primero contra las propias víctimas, luego a las mujeres trabajadoras, y finalmente al conjunto de la población pobre, migrante y morena, y tiene como efectos no solo el terror y la desmoralización, sino también el obligar a luchar en un terreno que no sea el de las reivindicaciones de tipo económico, contra la explotación, sino en la búsqueda de justicia por los crímenes padecidos. Esta situación se ve agravada por un discurso político y mediático que intenta culpabilizar a las víctimas y garantizar la impunidad de los crímenes.

En ese marco, Falquet pone el acento en que la violencia femicida en territorios como Juárez no puede ser entendida sin vincular la cuestión de género con la de la clase y la raza, y permiten así pensar la reorganización neoliberal del trabajo. Por un lado, a través del vínculo entre la violencia contra las mujeres y la continuidad con la guerra antisubversiva llevada a cabo en los ' 70 contra las organizaciones de izquierda, mediante técnicas destinadas a producir terror. Por otro lado, a través de la pacificación de la mano de obra. En ese marco, además de la continuidad con la guerra contrainsurgente, Falquet propone un paralelismo entre la violencia semi-privada que se ejerce hoy contra las mujeres y la caza de brujas estudiada por Federici como parte de la acumulación originaria ${ }^{38}$. En ese sentido, lo que estaría en juego es no solo que las mujeres que trabajan fuera de su hogar se vean sometidas a condiciones de explotación extremas sino también que garanticen "la reproducción social de la

36 Ibidem, p. $45-46$

37 J. Falquet, op. cit., p. 86. Coincidente con dicho diagnóstico es el de Ricardo Antunes, quien señala que asistimos a una "precarización estructural del trabajo a escala global" que tiene como ejemplo extremo a los inmigrantes quienes son objeto no solo de formas de ultraexplotación sino también de discriminación en los países donde residen. R. Antunes, "La nueva morfología del trabajo y sus principales tendencias: Informalidad, infoproletariado, (in)materialidad y valor", en J. Estrada Álvarez (comp.), América Latina en medio de la crisis mundial: trayectorias nacionales y tendencias mundiales, Ciudad Autónoma de Buenos Aires, CLACSO, 2014, p. 24. Para un análisis pormenorizado de los espacios fronterizos en el capitalismo neoliberal cf. S. Mezzadra y B. Nielson, La frontera como método o la multiplicación del trabajo, Buenos Aires, Tinta Limón, 2016.

38 S. Federici, Calibán y la bruja. Mujeres, cuerpo y acumulación originaria, Madrid, Traficantes de sueños, 2010. 
fuerza de trabajo"39. En efecto, la guerra contra las mujeres y su autonomía sigue estando profundamente vinculada a la acumulación de capital y a la necesidad que este tiene del trabajo reproductivo a bajo costo o gratuito. En ese sentido, lxs trabajadorxs migrantes de la frontera norte de México expresan una situación de precariedad existencial que pareciera indispensable para el funcionamiento de la norma neoliberal en dichos territorios y que a la vez es impuesta por dicha norma ${ }^{40}$.

En ese contexto, Falquet también sitúa la violencia contra las mujeres en el marco de las resistencias que estas llevan a cabo frente a las nuevas formas de extractivis$\mathrm{mo}^{41}$. A este respecto, analiza la violencia contra las mujeres y las formas de resistencia y organización que surgieron en los últimos años en Guatemala. Precisamente el caso guatemalteco ilustra de manera palmaria la continuidad entre la guerra genocida de los 80 y las nuevas formas de desposesión. Como señala Falquet:

Las violencias relacionadas al extractivismo a menudo ocurren en los mismos lugares de las masacres anteriores, incluso afectando a veces a lxs sobrevivientes directxs del genocidio. Son perpetradas por los mismos actores (policía, ejército, seguridad privada de las empresas), que actúan conjuntamente, con una impunidad comparable al período de la guerra y con el mismo objetivo: intimidar a la población y expulsarla de las zonas en cuestión. Y volvemos a encontrar también el uso de las violencias sexuales contra las mujeres, que participan activamente de todas las luchas y son objeto de numerosas violencias ${ }^{42}$.

En ese marco, las luchas feministas e indígenas contra el extractivismo dieron origen en Guatemala a una nueva forma de feminismo comunitario que ha establecido y mostrado "las conexiones entre $e l$ extractivismo, la militarización, la guerra y (re)colonización, poniendo en el corazón de la lógica neoliberal actual, la larga historia del uso patriarcal y racista de la violencia"43.

En este sentido, a propósito de las luchas de las mujeres indígenas guatemaltecas, Falquet señala:

Lejos de verlas como violencias excepcionales, anónimas o ancladas en una misoginia transhistórica, esas luchas han subrayado la existencia de un verdadero

$39 \quad$ Ibidem, p. 108.

40 Desde el punto de vista de Butler, "precariedad" tiene un doble sentido. Como precariousness remite a una condición existencial que todos compartimos, mientras que precarity designa una condición inducida por las formas neoliberales de vida, es decir, "una condición impuesta políticamente merced a la cual ciertos grupos de la población sufren la quiebra de las redes sociales y económicas de apoyo mucho más que otros, y en consecuencia están más expuestos a los daños, la violencia y la muerte”. J. Butler, Cuerpos aliados y lucha política. Hacia una teoría performativa de la asamblea, Buenos Aires, Paidós, 2017, p. 40. Esta misma ambivalencia puede ser rastreada en la noción de desposesión como ser despojado de tierras y saberes o el despojarse de la propia identidad y soberanía del yo para actuar colectivamente. Cf. J. Butler y A. Athanasiou, Desposesión. Lo performativo en lo político, Buenos Aires, Eterna cadencia, 2017.

41 En otros trabajos nos hemos ocupado del neoextractivismo en América Latina como un tipo de práctica transversal a gobiernos de distinta orientación política que han continuado con una matriz de desarrollo desposesiva. Sin embargo, no habíamos hecho mención a la conexión que existe en muchos de nuestros países entre extractivismo y guerra colonial primero y neocolonial después. Una guerra que no tiene entonces como víctima principal a la naturaleza, cuyos derechos algunas constituciones regionales reconocen, sino también a las poblaciones campesinas e indígenas, y en particular a los cuerpos-territorios de las mujeres.

42 J. Falquet, op. cit., pp. 134-135

43 J. Falquet, op. cit., p. 140. 
continuum de violencias contra las mujeres, principalmente indígenas pero no solamente contra ellas, antes y después de la guerra. [...] Han evidenciado su carácter instrumental: este continuum de violencias constituye el instrumento de las instituciones (Estado, ejército, multinacionales) que han estado llevando a cabo contra las mujeres, especialmente indígenas, una verdadera guerra de baja intensidad (basada en el uso del terror contra la población civil) de larga duración. [...] Pueden verse en esta violencia varios objetivos entrelazados: traumatizar a las mujeres mismas (y luego a sus familias y comunidad), desalojadas de un determinado territorio (siendo este mismo territorio y sus recursos lo que está en juego detrás de la violencia), y crear una mano de obra "libre" (privando a las poblaciones indígenas de sus recursos y de su territorio) que podrá ser empleada en las plantaciones, el empleo informal urbano o la migración (esencialmente para el trabajo doméstico y sexual) ${ }^{44}$.

Si bien se sitúan en un contexto bastante diferente, como es la periferia de la ciudad de Buenos Aires, los trabajos de Gago también ilustran la conexión entre la violencia contra las mujeres y las transformaciones en la economía y el mundo laboral, donde se conectan explotación financiera, precarización de la existencia, desposesión y asunción de formas de neoliberalismo desde abajo por parte de poblaciones precarizadas como lxs trabajadorxs migrantes ${ }^{45}$. En ese sentido, sus trabajos destacan el modo en que las finanzas explotan desde el exterior una cooperación social que se da por fuera de la relación salarial y a la que reconocen su productividad, dando lugar a nuevas formas de extractivismo ${ }^{46}$, del cual las mujeres son las principales afectadas, en la medida en que sostienen la reproducción social. Incluso el Estado, que ya no puede garantizar la inclusión a través del trabajo pero sí habilitar canales de consumo, otorga subsidios que están bancarizados y se erige en garante último de dicha explotación por parte de las finanzas en los barrios periféricos. En este sentido, si por un lado se reconoce mínimamente el trabajo reproductivo a través de la Asignación Universal por $\mathrm{Hijo}^{47}$, este tipo de subsidios que no aseguran dicha reproducción, funcionan como garantía para la toma de deuda, terreno en el que el propio Estado ha incursionado en 2017 a través de los Créditos Argenta (ahora llamados Créditos

\footnotetext{
Ibidem, p. 141-142.

V. Gago, La razón neoliberal, Buenos Aires, Tinta Limón, 2014.

V. Gago \& S. Mezzadra, op. cit.

47 La AUH es una asignación monetaria mensual por cada hijo menor de 18 años (hasta 5 niños) y sin límite de edad para niños con discapacidad que es otorgada por el Estado argentino a padres desocupados o que trabajan en empleos no registrados y de muy bajos ingresos, cuya obligación es enviar los niños a la escuela y vacunarlos. Se puede solicitar desde el momento del nacimiento y la percibe uno de los padres, priorizando a la madre. La existencia de dicho seguro social no deja de generar críticas en sectores del partido político que hoy gobierna el país (Cambiemos) y su electorado, máxime en un contexto de ajuste y búsqueda de reducción del gasto público. En los discursos de varios referentes de la fuerza gobernante, se señala que las mujeres se embarazan para cobrar una asignación, a pesar de que el $80 \%$ de las familias que la cobran no tienen más de dos hijos y que dicho subsidio que en Agosto de 2018 es de \$1578, equivalente a 40 USD, está muy lejos de cubrir una canasta básica que se estima entre \$19.601 (Indec, Junio de 2018) y \$32.529 (CESyAC, Rosario). En esos discursos, la “mujer aparece como un ser calculador que utiliza su maternidad como un modo de obtener un rédito económico, lucrando con sus hijxs. Esta acusación está dirigida de manera directa a los sectores populares, puesto que no se sostiene lo mismo respecto de los sectores medios que perciben las asignaciones familiares". Meritano, Silvina. "La deuda como técnica de gestión". Texto presentado en las VIII Jornadas Debates Actuales de la Teoría Política Contemporánea, Mendoza, 2017 a publicarse en Andrea Torrano et. al., Sujetos sitiados. Biopolitica, Monstruosidad y Neoliberalismo, Córdoba, Conicet, 2018.
} 
Anses) $)^{48}$. Lo interesante para nuestro tema es la conexión que establece Gago, en el marco de su trabajo en el colectivo "Ni una menos", entre el endeudamiento de las mujeres y la imposibilidad que ello implica de sustraerse a la violencia machista. En ese sentido, el Documento del 3 de Junio de 2017 señala que "las deudas no nos dejan decir no cuando queremos decir no" y que la "violencia machista se hace aun más fuerte con la feminización de la pobreza y la falta de autonomía económica que implica el endeudamiento" 49 .

En efecto, la creciente violencia contra las mujeres se da en una situación de fin del patriarcado del salario que, lejos de liberar a las mujeres, las somete doblemente: a la violencia de masculinidades en crisis por su imposibilidad de seguir siendo proveedoras y a la violencia de la deuda que muchas mujeres se ven forzadas a contraer, con la compulsión a encontrar los medios de reembolso. Sin embargo, como reconoce el documento de "Ni una menos", la deuda pública también afecta especialmente a las mujeres, en la medida en que las condicionalidades que ella supone, como reducción de los salarios y subsidios, recortes a la salud y la educación públicas, mayor precarización laboral y desempleo, etc. ponen en jaque a las economías familiares y afectan de manera más dramática a las mujeres ${ }^{50}$. En ese marco de precariedad generada por la deuda, se viabiliza una recolonización del cuerpo-territorio de las mujeres, que quedan expuestas a distintas formas de violencia, que en el extremo se manifiesta en el femicidio ${ }^{51}$.

En suma, con los aportes de Segato, Valencia, Falquet y Gago, vemos que la violencia que tiene a determinados grupos de subjetividades femeninas como blanco

48 Los créditos Anses son créditos personales para los jubilados, pensionados y quienes cobran Asignaciones por Hijo, financiados por el Fondo de Garantía de Sustentabilidad (FGS) de ANSES (Administración Nacional de Seguridad Social). Dichos créditos que tienen una tasa subsididada (en torno al $40 \%$ nominal anual y con visos de aumentar al son de la inflación y las corridas cambiarias) son otorgados en reconocimiento de la emergencia económica y social que atraviesan dichos sectores, y representan una clara expresión del reemplazo del derecho al bienestar por el derecho a endeudarse que tan bien ha ilustrado M. Lazzarato, op. cit.

49 "Vivas y desendeduadas nos queremos". Texto escrito para la acción de calle "Las insumisas de las finanzas" del viernes 2 de junio, previa a la Marcha del "Ni Una menos", el sábado 3 de junio 2017.

50 Cabe recordar que la deuda pública argentina, sumando todos sus componentes, aumentó en más de 200.000 millones de dólares desde la asunción de la alianza Cambiemos en Diciembre de 2015, en un contexto de inflación que superó el 100\% desde esa fecha a la actualidad. Dicha situación, sumado a un récord histórico de déficit comercial y de balanza de pagos y devaluación no programada del peso habilitó una nueva intervención de la economía por parte del Fondo Monetario Internacional, cuyos planes de ajuste y la recesión consiguiente también tendrán a las jefas de hogar pobres como principales afectadas. De hecho, estas crisis de deudas y salvatajes condicionados por el FMI nos recuerdan los años 1980, que son analizados en D. Libreros Caicedo y D Carrero Barón, "Financiarización, crecimiento inestable y vulnerabilidad económica en América latina y Colombia 1990-2013”, en J. Estrada Álvarez, op. cit., pp. 127-150.

51 A diferencia de lo que sucede en las geografías más violentas del continente, en Argentina el 75\% de los femicidios suponen una relación de la víctima con su victimario. Sin embargo, Gago establece una clara conexión entre violencia de género y las transformaciones sociales, económicas y políticas sufridas por nuestra región. En ese sentido, señala que la violencia contra las mujeres tiene que ver con al menos cuatro cuestiones: 1 . la implosión de la violencia en los hogares como efecto de la crisis del varón proveedor, donde la humillación sufrida por los varones en el ámbito laboral tiene consecuencias en la violencia hogareña. 2. La proliferación de economías ilegales que suponen otras formas de provisión de recursos, lógicas de autoridad y umbrales de violencia. 3. El saqueo de los bienes comunes, y en especial de las tierras que podrían dar autonomía material a otras economías, sobre todo campesinas. 4. El rol ya comentado de las finanzas como elemento que explota la creatividad y el trabajo de los sectores populares. Cf. V. Gago, “¿Hay una guerra “en” el cuerpo de las mujeres? Finanzas, territorios y violencias". Conferencia pronunciada el 14 de junio de 2017 en la Universidad Torcuato Di Tella, en el marco del seminario de lectura, Programa de Artistas 2017, Buenos Aires, disponible en https:// vimeo.com/231128558. Texto publicado en inglés en Viewpoint Magazine, 7 de marzo de 2018 https://www. viewpointmag.com/2018/03/07/war-body-women-finance-territory-violence/ 
privilegiado, desatada especialmente durante las décadas neoliberales en la región, debe ser situada en una genealogía más profunda de las relaciones entre guerras y capital, especialmente en lo tocante a los regímenes autoritarios de los '70 y a las distintas etapas de la colonización de nuestros territorios y poblaciones. A la vez, dicha violencia tiene funciones precisas de desposesión y gestión de la fuerza de trabajo que son propias de esta nueva etapa del capitalismo. Es precisamente la desposesión la que produce la imposibilidad de reproducir la vida por fuera del mercado, destruyendo la autonomía de las mujeres pobres, y lo que, reeditando elementos de la acumulación originaria, busca generar las condiciones que las obliguen a combinar trabajo productivo y reproductivo al menor costo posible ${ }^{52}$. Al mismo tiempo, esta precarización existencial, sumada a las seducciones del marketing y el hiperconsumo, incita a niños y jóvenes sin futuro, despreciados y estigmatizados, a ganarse la vida como profesionales de la violencia en el marco de las economías criminales. En ese contexto, el círculo se cierra sobre sí mismo. Al igual que con la deuda, que afecta de manera especial a las mujeres pobres, la violencia contra las mujeres supone la continuidad de la guerra y la desposesión por otros medios, utilizando crueles mnemotécnicas sobre los cuerpos vejados, mutilados, destruidos.

\section{La guerra contra las mujeres y las luchas por lo común}

A la luz de lo ya comentado, no es casual que en América Latina la violencia estatal y la de las bandas mafiosas para-estatales, que en muchos casos se han ensañado con las mujeres, se haya desplegado con una fuerza inusitada en la etapa neoliberal, marcada por una disrupción del tejido comunitario y organizacional que sostenía a muchas de estas sociedades, y a las transformaciones concomitantes en el mundo del trabajo, que pone en crisis al patriarcado del salario ${ }^{53}$. El mercado global de la droga y la criminalidad a ella asociada se despliegan justamente en estas últimas décadas, donde el tráfico de drogas, armas y gente se transforman en las actividades económicas más rentables y hegemónicas en lo que Segato llama "segunda realidad". En muchos países de nuestra región, los recursos de esta realidad para-estatal son tan grandes como los de la economía formal vinculada a la ciudadanía y se entretejen con ella de múltiples maneras, incluido el lavado de dinero, donde las guaridas fiscales tienen un rol decisivo. Por eso mismo la informalidad armada es uno de los factores más dinámicos de los que se nutre la acumulación de capital en las economías latinoamericanas, fuertemente ligadas a todo tipo de industrias extractivas (desde la minería al narcotráfico).

Al mismo tiempo, estas nuevas formas de guerra tienen una inocultable dimensión contrarrevolucionaria que va en sintonía con el proyecto político neoliberal. Si

52 Sobre el debate en torno al carácter continuo de la acumulación originaria y los nuevos cercamientos, a partir de lo cual Harvey elabora la noción de acumulación por desposesión, véase, por ejemplo, Midnight Notes, 10 "The New Enclosures" (1990), disponible en http://www.midnightnotes.org/newenclos.html y también el número 26 de Revista Theomai (2012), que contiene valiosos artículos al respecto de M. De Angelis, M. Perelman, W. Bonefeld y otros. Específicamente en relación a la acumulación originaria y expropiación de cuerpos y saberes de las mujeres, véase S. Federici, Calíban, cit. Esta misma autora relaciona además, analizando tempranamente el caso africano, la deuda como dispositivo de poder que lleva a una nueva fase de la acumulación originaria. Federici, Silvia. "The Debt crisis, Africa and the new enclosures". Midnight Notes, no. 10 (1990).

53 Concepto utilizado por S. Federici, El patriarcado del salario. Críticas feministas al marxismo, Madrid, Traficantes de sueños, 2018. 
la primera etapa del neoliberalismo, fuertemente signada por el abuso de la violencia estatal, tuvo por objeto acabar con cualquier posibilidad del socialismo e incluso con la breve historia del reformismo del capital ${ }^{54}$, la etapa actual aparece muy ligada en Latinoamérica a formas para-estatales de guerra en el seno de las poblaciones que emergen como respuestas a las luchas por la autonomía productiva y política, que podemos conceptualizar como luchas por lo común.

En efecto, la búsqueda de defender y promover bienes comunes y espacios de decisión colectiva ligados a su gestión son la respuesta que, desde los sectores populares, se ha dado a las prácticas desposesivas y al gobierno neoliberal de las poblaciones. Este ha respondido con distintas estrategias, desde el intento de cooptación de movimientos contestatarios a la intervención armada directa. No casualmente, la "guerra al narcotráfico" impulsada por la CIA y la DEA en México y Colombia (y que se intenta implantar en otros países de la región) se despliega después de grandes luchas sociales, como la emergencia del movimiento zapatista en México, la guerra del agua y del gas en Bolivia, las movilizaciones en Ecuador y Colombia y las organizaciones populares en Brasil y Argentina que posibilitaron algunos cambios políticos en la región. Tampoco es casual, en ese marco, el asesinato sistemático de dirigentes sociales, en países como Colombia, y de periodistas independientes en México, ni la sanción por doquier de leyes antiterroristas. Dichas guerras han dejado decenas de miles de muertos y desaparecidos con una incidencia masiva de asesinatos políticos ${ }^{55}$.

En ese marco, distintos movimientos sociales, especialmente feministas, apuestan por nuevas formas de construcción colectiva de lo común frente a las lógicas extractivas, desposesivas y homicidas que se han ido imponiendo. No es casual que, de manera independiente, en dos países de mayoría indígena como Bolivia y Guatemala, haya surgido un feminismo comunitario, que no solo se ha opuesto a las prácticas extractivas que afectan de manera directa a las mujeres, sino que también se ha abocado a lo que Segato llama "retejer comunidad". En ese marco, la antropóloga opone el proyecto histórico de las cosas al proyecto histórico de los vínculos, algo que se puede relacionar con los efectos del hiperconsumismo señalados por Valencia ${ }^{56}$ :

[...] el deseo de las cosas produce individuos, mientras el deseo del arraigo relacional produce comunidad. Este último es disfuncional al proyecto histórico del capital, pues el investimento en los vínculos como forma de felicidad blinda los lazos de reciprocidad y el arraigo comunal y torna a los sujetos menos vulnerables al magnetismo de las cosas. Solo con sujetos desgajados y vulnerables, el mundo de

54 Cf. Davies, op. cit; Alliez y Lazzarato, op. cit., J. Villarreal, "Los hilos sociales del poder”, en Jozami, E. et al, Crisis de la dictadura argentina. Política económica y cambio social, Buenos Aires, Siglo XXI, 1985.

55 Entre los gobiernos de Peña Nieto y Calderón (2006-2017), México sumó 250.000 muertos por homicidio, siendo declarado en 2016 por una organización Británica como el país más letal después de Siria (que estaba en una de las etapas álgidas de la guerra aun en curso). En 2007, año posterior a la asunción de Calderón, se dio la tasa de homicidios per cápita más baja de los últimos 20 años, con 7.8 cada 100.000 hab. (datos BN). Solamente en 2017, año más violento hasta le fecha, hubo 29.918 homicidios y la tasa llegó a 20,5.

56 Como señala Macy Louise Pratt, "la incapacidad del neoliberalismo para generar pertenencia, colectividad y un sentido creíble de futuro produce, entre otras cosas, enormes crisis de existencia y de significados que están siendo vividas por los no consumistas y los consumistas del mundo en formas que la ideología neoliberal no puede predecir ni controlar". "Globalización, desmodernización y el retorno de los monstruos", Tercer Encuentro de Performance y Política, Universidad Católica, Lima, 2002, cit. en S. Valencia, op. cit., p. 21 
las cosas se impone: las lecciones de las cosas, la naturaleza cosa, el cuerpo cosa, las personas cosas, y su pedagogía de la crueldad que va imponiendo la estructura psicopática, de pulsión no vincular sino instrumental, como personalidad modal de nuestro tiempo. Por eso sugiero que el camino de la historia será el de retejer y afirmar la comunidad y su arraigo vincular. Y por eso creo que la política tendrá que ser a partir de ahora femenina.

Si bien oponer las cálidas relaciones a las frías cosas puede dar lugar a cierta nostalgia por una mítica comunidad como lugar de reencuentro y $\operatorname{armoní}^{57}$, y si bien sería casi imposible ponerse de acuerdo en lo que sería una política femenina, pues no hay ninguna esencia de lo femenino a la que podamos apelar, cabe señalar que el feminismo comunitario o las corrientes comunitario-populares que han proliferado en nuestra región en las últimas décadas no proponen ningún esencialismo identitario sino un intento de practicar una política basada en la autonomía, el autogobierno, la reciprocidad y la gestión conjunta de aquello que es necesario para la reproducción de la vida. Es decir que lo que define lo común no es una identidad sino una praxis compartida en un marco que cuestiona la mercantilización de todo lo existente, para sostener o recuperar el valor de uso de las cosas ${ }^{58}$.

Este tipo de luchas y paradigmas han permitido que el buen vivir propio de las concepciones andinas tenga un reconocimiento constitucional en países como Ecuador y Bolivia, señalando hacia la posibilidad de un nuevo tipo de relación entre lo público y lo común, la vida humana y su entorno, etc. que aún espera ser realizado.

En ese sentido, debemos señalar que al interior de Latinoamérica y del feminismo coexisten realidades, necesidades y demandas muy diversas y que el acento puesto en la autonomía no debería llevar al abandono del Estado como terreno de lucha, ya que ha sido precisamente su sumisión a las lógicas del capitalismo neoliberal la que ha permitido en buena medida el despliegue actual de la guerra contra las mujeres y poblaciones precarizadas en general. Por ello, más allá de la dicotomía entre autonomía y cooptación, y en relación a la experiencia de los sectores populares urbanos en Argentina que se vieron obligados a una re-socialización de la reproducción social que supuso nuevas formas de cooperación y gestión de ciertos subsidios, Gago plantea que

[...] lo común; es decir, una pluralidad de procesos de creación que va de lo material y físico a procesos inmateriales, afectivos e intelectuales (...) no es un conjunto de bienes preexistentes, sino una dinámica popular de invención y reapropiación. Despliega una inteligencia para negociar con el Estado y, en ese punto, no plantea una autonomía ingenua, más bien se trata de propuestas que coexisten a la vez que contestan y tensionan la subjetividad patriarcal y la construcción del cuerpo heteronormativo inscrito en la división sexual del trabajo, en la naturalización de una economía mercadocéntrica y en una política instituida desde lo representativo ${ }^{59}$.

57 Algo ya largamente desconstruido en tanto que proyección retroactiva sumido en la dialéctica entre un mítico origen y el intento por recuperarlo por textos como J-L. Nancy, La comunidad desobrada, Madrid, Arena, 2001 o R. Esposito, Communitas. Origen y destino de la comunidad, Buenos Aires, Amorrortu, 2003.

58 Cf. P. Dardot y Ch. Laval, Común. Ensayo sobre la revolución en el siglo XXI, Barcelona, Gedisa, 2015 y R. Gutiérrez Aguilar, Los ritmos del pachakuti, México, Bajo tierra, 2009.

59 N. Quiroga Díaz \& V. Gago. "Los comunes en femenino. Cuerpo y poder ante la expropiación de las economías para la vida." Economía y Sociedad, 19.45 (2014). 
Retejer comunidad o construir lo común, con las complejidades que cada situación específica supone, aparecen así como consignas de un devenir posible más allá de las lógicas necropolíticas del capitalismo neoliberal, un sistema de dominación que no solo produce precariedad existencial sino que además parece haberse ensañado con las poblaciones más castigadas ${ }^{60}$. En dicho marco, la guerra contra las mujeres se vuelve paradigmática, puesto que es una guerra no solo por sostener un patriarcado herido por la precarización laboral sino, fundamentalmente, contra la capacidad de, y el control sobre, la reproducción de la vida por fuera de las lógicas del capital. Es una guerra que busca obstaculizar una reinvención de lo común y por ende, un porvenir más allá del capitalismo. Tal vez por eso se va instalando en las calles de nuestra región la consigna de que la revolución será feminista o no será. 